\title{
Longitudinal Risk Factors for Cyberbullying in Adolescence
}

\author{
FABIO STICCA $^{1 *}$, SABRINA RUGGIERI $^{2}$, FRANÇOISE ALSAKER $^{2}$ and \\ SONJA PERREN ${ }^{1}$ \\ ${ }^{1} J a c o b s$ Center for Productive Youth Development, University of Zurich, Zurich Switzerland \\ ${ }^{2}$ Department of Psychology, University of Bern, Bern Switzerland
}

\begin{abstract}
Cyberbullying has emerged as a new form of antisocial behaviour in the context of online communication over the last decade. The present study investigates potential longitudinal risk factors for cyberbullying. A total of 835 Swiss seventh graders participated in a short-term longitudinal study (two assessments 6 months apart). Students reported on the frequency of cyberbullying, traditional bullying, rule-breaking behaviour, cybervictimisation, traditional victimisation, and frequency of online communication (interpersonal characteristics). In addition, we assessed moral disengagement, empathic concern, and global self-esteem (intrapersonal characteristics). Results showed that traditional bullying, rule-breaking behaviour, and frequency of online communication are longitudinal risk factors for involvement in cyberbullying as a bully. Thus, cyberbullying is strongly linked to real-world antisocial behaviours. Frequent online communication may be seen as an exposure factor that increases the likelihood of engaging in cyberbullying. In contrast, experiences of victimisation and intrapersonal characteristics were not found to increase the longitudinal risk for cyberbullying over and above antisocial behaviour and frequency of online communication. Implications of the findings for the prevention of cyberbullying are discussed. Copyright $(2) 2012$ John Wiley \& Sons, Ltd.
\end{abstract}

Key words: cyberbullying; traditional bullying; victimisation; longitudinal; risk factors

The rapid development of modern communication technologies over the last decade has led to a number of new possibilities of online interaction. Especially because smart phones conquered the market, an increasing number of people have mobile access to the Internet and may be online around the clock. In Switzerland, 95\% of adolescents aged 12-19 years have Internet access at home, whereas $75 \%$ also have access to the Internet from their own room. Moreover, virtually every Swiss adolescent owns a mobile phone (Willemse, Waller, \& Süss, 2010).

*Correpondence to: Fabio Sticca, Jacobs Center for Productive Youth Development, Universität Zürich, Culmannstrasse 1, CH-8006 Zürich, Switzerland.

E-mail: fabio.sticca@uzh.ch 
This evolution in communication technologies has also led to problematic patterns of interpersonal communication. One such problematic pattern is cyberbullying. Cyberbullying can be seen as a modern form of bullying, defined as an aggressive behaviour that is intentionally (hostile intent) and repeatedly (repetition) carried out against a defenseless victim (power imbalance; Olweus, 1993). The modern element of cyberbullying is the use of electronic forms of communication (e.g. the internet or mobile phones; Smith et al., 2008). However, repetition and power imbalance are features of traditional bullying that may be hard to conceptualise in the context of cyberbullying (Dooley, Pyzalski, \& Cross, 2009; Nocentini et al., 2010; Vandebosch \& Van Cleemput, 2009). In fact, repetition and power imbalance are sometimes omitted from the definition and operationalisation of cyberbullying, making it hard to compare existing studies with each other (for review, see Tokunaga, 2010). Althou gh cyberbullying may be seen as bullying by electronic means, there are some features that distinguish cyberbullying from traditional bullying: (i) the perception of perpetrators' anonymity, (ii) the potentially infinite audience, (iii) the bully's inability to observe the target's immediate reaction, and (iv) the absence of time and space constraints (Slonje \& Smith, 2008).

Over the last decade, cyberbullying has attracted much attention both in the media and in scientific research. This has been fostered by a number of suicide deaths that were motivated by severe experiences of cyberbullying (e.g. ABC News, 2007). Nonetheless, research on cyberbullying is as young as the phenomenon itself, and results obtained so far are quite fragmented. According to Tokunaga (2010), current cyberbullying research suffers from several problems: (i) unresolved issues of definition and measurement of cyberbullying, (ii) lack of theoretical background, (iii) overreliance on cross-sectional data, and (iv) a tendency to take simplistic approaches. The present study aimed to overcome some of these limitations by analysing longitudinal data and by simultaneously investigating a range of interpersonal (e.g. traditional bullying) and intrapersonal (e.g. global self-esteem) characteristics as potential longitudinal risk factors for involvement in cyberbullying. Note that in the following the terms cyberbullying and traditional bullying are used to indicate bully status in cyberbullying and traditional bullying, respectively. Similarly, the terms cybervictimisation and traditional victimisation are used to indicate victim status in cyberbullying and traditional bullying, respectively.

\section{Risk factors for cyberbullying}

Current empirical findings on risk factors associated with cyberbullying have been obtained from cross-sectional studies (Sourander et al., 2010). As cross-sectional studies cannot distinguish cause and effect, we do not know which cross-sectional correlates of cyberbullying can be considered as longitudinal risk factors, that is, as factors that increase the odds of engaging in cyberbullying in the future. The current study investigates longitudinal associations between cyberbullying and a number of potential risk factors. We included a range of variables found to be associated with cyberbullying and other forms of antisocial behaviour (e.g. traditional bullying) in previous cross-sectional research. Interpersonal characteristics included antisocial behaviours (i.e. traditional bullying and rule-breaking behaviours), experiences of victimisation (i.e. cybervictimisation and traditional victimisation), and frequency of online communication. Intrapersonal characteristics included gender, moral disengagement, empathic concern, and global self-esteem. 
Traditional bullying. One of the most consistent findings in cyberbullying research is the significant overlap between involvement in cyberbullying and traditional bullying. Many cyberbullies are also traditional bullies (Smith, 2011b; Smith \& Slonje, 2010). Accordingly, cyberbullying may be seen as an additional way to attack people rather than as something conceptually different (Gradinger, Strohmeier, \& Spiel, 2010; Raskauskas \& Stoltz, 2007). To investigate specific risk factors for cyberbullying over and above traditional bullying (i.e. pure cyberbullying), it is crucial to take this empirical (and conceptual) overlap into account (i.e. control for concurrent traditional bullying).

Rule-breaking behaviour. Another form of antisocial behaviour found to be associated with cyberbullying is rule-breaking behaviour: Ybarra and Mitchell (2004) found that cyberbullies display increased rule-breaking behaviours (e.g. damaging property, consumption of cigarettes/alcohol), thus pointing to the need to elucidate the longitudinal role of this potential risk factor.

Cybervictimisation and traditional victimisation. Cybervictimisation has been found to be positively associated with cyberbullying (Bauman, 2009; Mitchell, Finkelhor, Wolak, Ybarra, \& Turner, 2011), and Ybarra and Mitchell (2004) proposed that traditional victims would use cyberbullying as a way to retaliate. However, this result was not replicated in more recent studies (Raskauskas \& Stoltz, 2007; Slonje \& Smith, 2008; Vandebosch \& Van Cleemput, 2009). Nonetheless, Law, Shapka, Hymel, Olson, and Waterhouse (2012) have suggested that in cyberbullying dynamics there are many adolescents who are both cyberbullies and cybervictims at the same time. The authors postulated that this may be due to the fact that there is less direct contact and that power imbalances are not as salient and influential in cyberspace as in the real world. Therefore, reacting in an aggressive manner to an experience of victimisation may be more likely than in the real world.

Frequency of online communication. Risky Internet usage has been found to be a significant predictor of involvement in cyberbullying (Erdur-Baker, 2010). Furthermore, cyberbullies spend significantly more time online than do their peers (Erdur-Baker, 2010), especially using instant messaging programs (Ybarra \& Mitchell, 2004). Frequent online communication can thus be considered as a risk factor for cyberbullying in the sense of an exposure effect.

Gender. Although previous findings clearly show that boys engage in more physical, verbal, and relational bullying than do girls (Olweus, 2010), results for gender differences in cyberbullying are mixed. Some studies report higher involvement of boys (e.g. Erdur-Baker, 2010; Slonje \& Smith, 2008), whereas some find no significant differences (e.g. Patchin \& Hinduja, 2006; Smith et al., 2008) and others find girls to be more involved than boys (Kowalski \& Limber, 2007).

Moral disengagement. Previous research showed that moral disengagement is associated with antisocial behaviour in children and adolescents (Yadava, Sharma, \& Gandhi, 2001). Traditional bullies stress the positive outcomes of aggressive acts for the self by distorting the consequences and by ignoring the victim (Menesini et al., 2003; Perren, GutzwillerHelfenfinger, Malti, \& Hymel, 2011). These and other moral disengagement strategies were also found to be positively associated with cyberbullying (Pornari \& Wood, 2010). However, Pornari and Wood (2010) argued that although moral disengagement is a correlate of both cyberbullying and traditional bullying, cyberbullying demands lower levels of moral 
disengagement because of its greater anonymity and because the victim's reactions are not directly observable. There are also studies indicating that moral disengagement may not be associated with cyberbullying at all, especially if traditional bullying is taken into account (Perren \& Gutzwiller-Helfenfinger, 2012).

Empathic concern. There is strong evidence for a positive relation between antisocial behaviour and low levels of empathy (Jolliffe \& Farrington, 2004). However, only low affective empathy was found to be associated with bullying (Caravita, Di Blasio, \& Salmivalli, 2009; Jolliffe \& Farrington, 2011), whereas low cognitive empathy was not (Jolliffe \& Farrington, 2011). These results indicate that bullies are able to understand the victim's emotions but they do not share them (Sutton, Smith, \& Swettenham, 1999). In relation to cyberbullying, it was shown that cyberbullying is associated with lower levels of both affective and cognitive empathy (Ang \& Goh, 2010; Schultze-Krumbholz \& Scheithauer, 2009) and also with lower levels of global empathy (Steffgen, König, Pfetsch, \& Metzler, 2012).

Global self-esteem. The direction of the relation between self-esteem and bullying is not consistent for bullies. Positive, negative, and non-significant associations between traditional bullying and self-esteem have all been found (for review, see Patchin \& Hinduja, 2010). For cyberbullying, the results of a cross-sectional study by Patchin and Hinduja (2010) revealed that cyberbullies report lower levels of self-esteem than do non-involved students. In summary, the role of self-esteem as a longitudinal risk factor for cyberbullying has yet to be explored.

\section{Research questions}

The present study aims to move beyond the cross-sectional nature of the literature on cyberbullying (Tokunaga, 2010) and give an insight into the relative importance of different longitudinal risk factors for cyberbullying.

Based on the cross-sectional results presented earlier, we hypothesise that interpersonal characteristics (i.e. traditional bullying, rule-breaking behaviours, traditional victimisation, cybervictimisation, frequent online communication) and lower levels of empathic concern increase the odds of future involvement in cyberbullying. In addition, we will explore the role of gender, moral disengagement, and global self-esteem.

As there is a strong overlap between cyberbullying and traditional bullying (Smith, 2011a), it is necessary to account for concurrent traditional bullying to analyze which risk factors predict changes in cyberbullying, over and above concurrent traditional bullying. Accordingly, we will control for the effect of previous involvement in cyberbullying (i.e: consider residual changes in cyberbullying) and for the effect of concurrent involvement in traditional bullying.

\section{METHOD}

\section{Procedure}

Data from a longitudinal study carried out in Switzerland (netTEEN) will be presented in this article. Data from the first (November/December 2010) and the second (May 2011) wave of data assessment are included. As required by Swiss legislation, permission to 
conduct the study was obtained from the respective school councils. School directors and teachers from the selected schools volunteered, and parents were told about the study and asked to inform the teachers if they did not want their children to participate (passive consent). The parents of four adolescents refused to participate. The participants were informed about the survey's procedure and goal and were given the opportunity to refrain from participation with no negative consequences (informed oral consent). Students who did not want to participate were offered another activity during the relevant school period.

An electronic self-report questionnaire was administered in classrooms on netbooks. For students who were absent during the classroom assessment, a personal login and password were distributed. These students completed an online version of the questionnaire.

\section{Sample}

Three Swiss cantons (Wallis, Thurgau, Ticino) with integrative school systems were randomly selected from the 15 cantons with integrative school systems. In integrative school systems, students are not divided into higher and lower performance classrooms. By selecting only schools with integrative school systems, we therefore avoided systematic effects from the academic performance level of the class. In each of the three cantons, four schools with at least three classrooms were randomly selected, and each school was represented in the present study by three to four classrooms, resulting in a total of 43 classrooms. In the first assessment 835 Swiss adolescents (49\% girls, mean age $=13.2$ years, $S D=0.64$ years) participated in the study. A total of 820 students also participated in the second assessment. Attrition was mainly due to adolescents having moved schools.

\section{Measures}

Cyberbullying. A scale covering a set of different aggressive behaviours performed using electronic means was developed for this study. A detailed list of the items can be found in the APPENDIX. The same items were used to assess both cyberbullying (six items; $\alpha=.62$ ) and cybervictimisation (six items; $\alpha=.76$ ). Participants rated how often they had performed (cyberbullying) and how often they had suffered (cybervictimisation) these behaviours in the past 4 months. Possible responses ranged from 1 (never) to 5 (almost daily). Due to its high degree of skew at the upper end of the scale, cyberbullying was dichotomised. Those participants who scored higher than one on at least one of the cyberbullying items were classified as cyberbullies. Those participants who scored higher than one on at least one of the cybervictimisation items were classified as cybervictims.

Traditional bullying. Involvement in traditional bullying as a bully or as a victim was assessed using an adapted version of a validated traditional bullying and victimisation scale (Alsaker, 2003). This scale consists of 12 items encompassing a set of different aggressive behaviours (e.g. laughing at people, insulting, excluding, or hitting someone). Six items were used to assess traditional bullying $(\alpha=.63)$, and six items were used to assess traditional victimisation $(\alpha=.76)$. Participants were asked how often they had performed/suffered these behaviours in the past 4 months. Participants rated each item from 1 (never) to 5 (almost daily). To make the data comparable, we also dichotomised the traditional bullying, and the traditional victimisation scale used the same cut-off we used for cyberbullying (i.e. 1-2 times). 
Rule-breaking behaviour. Rule-breaking behaviour was assessed using an 8-item scale specifically developed for this study. The items described a variety of rule-breaking behaviours (e.g. destroying things, smoking, drinking, stealing, or cheating during tests). Participants were asked to indicate how often they had performed these behaviours in the past 4 months. Participants rated each item from 1 (never) to 5 (almost daily). Item scores were averaged to gain an overall score of rule-breaking behaviour $(\alpha=.75)$, with higher scores indicating more rule-breaking behaviour.

Frequency of online communication. Frequency of online communication was assessed using an 8-item scale specifically developed for this study. These eight items described a set of social online activities (e.g. phone calls, chatting). Participants were asked to indicate how often they had performed these activities in the past 4 months. Possible responses ranged from 1 (never) to 5 (almost daily). Scores for the eight items were averaged to create an overall score of frequency of online communication $(\alpha=.80)$, with higher scores indicating more online communication.

Moral disengagement. Participants were given two hypothetical bullying scenarios describing an adolescent excluding and humiliating a peer. After each scenario, the participants were given five (Scenario 1) and six (Scenario 2) statements (e.g. 'That schoolmate deserved it') and were asked if they agreed (Perren, Rumetsch, Gutzwiller-Helfenfinger, \& Malti, 2012). Responses ranged from 1 (not true) to 4 (true). Scores were averaged to obtain a single score for moral disengagement ( 11 items, $\alpha=.86$ ). Higher scores indicate higher levels of moral disengagement.

Empathic concern. A scale by Zhou, Valiente, and Eisenberg (2003), slightly adapted and translated into German (Malti, Gummerum, Keller, \& Buchmann, 2009), was used to assess empathic concern. Participants were given five statements about empathic feelings for other people in difficult situations (e.g. 'When I see other adolescents who feel bad, I empathize with them'). Participants rated the statements on a scale ranging from 1 (not true) to 4 (true). Item scores were averaged to gain a single score of empathic concern $(\alpha=.87)$, with higher scores indicating higher empathic concern.

Global self-esteem. An adapted German version of the Rosenberg Scale (Collani \& Herzberg, 2003) was used to assess global self-esteem. Participants rated 10 statements about their global self-esteem (e.g. 'All things considered, I am happy with myself') on a scale ranging from 1 (not true) to 4 (true). A mean score of all 10 items was calculated $(\alpha=.78)$. Higher means indicated higher global self-esteem.

\section{RESULTS}

\section{Descriptive results}

Table 1 shows the frequencies of the dichotomised variables, and the means and standard deviations of all other variables. Note that the mean of a dichotomised variable with scores of 0 and 1 represents the percentage of cases with a score of 1 (e.g. the percentage of cyberbullies).

The results show that cyberbullying is less prevalent than traditional bullying. The same was found for cybervictimisation and traditional victimisation. A comparison of involvement in cyberbullying at $t 1$ and at $t 2$ showed that $79.2 \%$ of participants were not involved in cyberbullying at either assessment, whereas $6.9 \%$ were involved both at $\mathrm{t} 1$ and at $\mathrm{t} 2$, $7.3 \%$ were involved only at $t 1$, and $6.7 \%$ were involved only at $t 2$. 
Table 1. Bivariate correlations between all study variables (Pearson's $r$ and Cranmer's $V$ )

\begin{tabular}{|c|c|c|c|c|c|c|c|c|c|c|c|c|c|c|}
\hline & $M^{\mathrm{a}}$ & $S D$ & 1 & 2 & 3 & 4 & 5 & 6 & 7 & 8 & 9 & 10 & 11 & 12 \\
\hline 1. Cyberbullying $\mathrm{tl}^{\mathrm{b}}$ & $14 \%$ & & 1 & $.43 * * *$ & $.30 * * *$ & $.28 * * *$ & $.17 * * *$ & $.39 * * *$ & $.27 * * *$ & $.21 * * *$ & $-13^{* * * *}$ & $-.12 * * * *$ & $.24 * * *$ & .01 \\
\hline 2. Cyberbullying $t 2^{b}$ & $13 \%$ & & & 1 & $.28 * * *$ & $.32 * * *$ & $.13 * * *$ & $.22 * * *$ & $.30^{* * * *}$ & $.20 * * *$ & -.03 & $-.12 * * * *$ & $.24 * * * *$ & -.05 \\
\hline 3. Traditional bullying $\mathrm{t}^{\mathrm{b}}$ & $57 \%$ & & & & 1 & $.38 * * *$ & $.35 * * *$ & $.16^{* * * *}$ & $.27 * * *$ & $.11 * *$ & -.06 & $-.14 * * *$ & $.31 * * * *$ & -.08 \\
\hline 4. Traditional bullying $\mathrm{t} 2^{\mathrm{b}}$ & $47 \%$ & & & & & 1 & $.19 * * *$ & $.12 * * *$ & $.25 * * *$ & $.16 * * *$ & -.04 & $-10 * * *$ & $.32 * * *$ & $-.07 *$ \\
\hline 5. Traditional victimisation $\mathrm{t} 1^{\mathrm{b}}$ & $69 \%$ & & & & & & 1 & $.27 * * *$ & $.14 * * *$ & -.01 & $-18 * * *$ & -.01 & .05 & -.04 \\
\hline 6. Cybervictimisation $t 1^{b}$ & $22 \%$ & & & & & & & 1 & $.20^{* * * *}$ & $.16 * * *$ & $-.22 * * *$ & -.06 & .12 **** & $.09 * *$ \\
\hline 7. Rule-breaking behaviour & 1.23 & 0.36 & & & & & & & 1 & $.30 * * *$ & $-.06 *$ & $-18 * * * *$ & $.36^{* * * *}$ & $-.12 * * *$ \\
\hline 8. Online communication & 3.02 & 0.99 & & & & & & & & 1 & .00 & -.05 & $.22 * * *$ & .07 \\
\hline 9. Global self-esteem & 1.81 & 0.54 & & & & & & & & & 1 & .05 & .04 & $-.10^{* *}$ \\
\hline 10. Empathic concern & 2.05 & 0.78 & & & & & & & & & & 1 & $-.35 * * *$ & $.33 *$ \\
\hline 11. Moral disengagement & 1.68 & 0.57 & & & & & & & & & & & 1 & $-.22 * * *$ \\
\hline 12. Gender (female) ${ }^{b}$ & $49 \%$ & & & & & & & & & & & & & 1 \\
\hline
\end{tabular}

Note $* p<.05 * * * 0.01 * * * * p<.001 ;$ 'The mean score of a dichotomous variable with scores of 0 and 1 represents the percentage of cases with a score of $1{ }^{b} \mathrm{Cranmer}$ 's $\mathrm{V}$ was used to compute correlations between dichotomous variables. 


\section{Bivariate associations}

Correlations between all variables were calculated to gain a descriptive overview of all associations (Table 1). Cyberbullying at $\mathrm{tl}$ is positively associated with all other variables except gender (no significant association) and is negatively correlated with empathic concern and self-esteem. Cyberbullying at $t 2$ is positively correlated with all variables except global self-esteem and gender (no significant association) and is negatively correlated with empathic concern.

\section{Analysis strategy for multivariate associations}

To investigate multivariate associations between potential risk factors and cyberbullying, a hierarchical approach consisting of one logistic regression with four models was adopted. Cyberbullying at $t 2$ was used as a dependent variable. The order of inclusion of the independent variables was based on the strength of their bivariate association with involvement in cyberbullying at $t 2$ while maintaining the division of interpersonal and intrapersonal characteristics. In addition, interpersonal characteristics were sequentially entered in three steps to look progressively at the role of antisocial behaviours, experiences of victimisation, and frequency of online communication. In Model 1, traditional bullying and rule-breaking behaviour were entered as independent variables. (interpersonal characteristics). In Model 2, cybervictimisation and traditional victimisation were entered as interpersonal characteristics. In Model 3, frequency of online communication was entered as interpersonal characteristic. Finally, in Model 4, gender, moral disengagement, empathic concern, and global self-esteem were entered as intrapersonal characteristics. In all models, cyberbullying at $t 1$ and traditional bullying at $\mathrm{t} 2$ were included as control variables.

\section{Results of multivariate logistic regression analyses}

Table 2 shows the results of longitudinal multivariate logistic regression analyses. Results from Model 1 showed that, when controlling for cyberbullying at $\mathrm{t} 1$ and traditional bullying at $t 2$, traditional bullying at $t 1$ and rule-breaking behaviours at $t 1$ independently increased the odds of engaging in cyberbullying at 12 . Those adolescents who display antisocial behaviours at $\mathrm{t} 1$ are at increased risk of being involved in cyberbullying at $\mathrm{t} 2$.

When adding experiences of victimisation to the model, neither cybervictimisation nor traditional victimisation was found to significantly increase the odds of engaging in cyberbullying at $t 2$ over and above the effects of antisocial behaviours, which were still statistically significant.

In Model 3, frequency of online communication was found to increase the odds of engaging in cyberbullying over and above antisocial behaviours, which again were statistically significant, and experiences of victimisation, which were still not statistically significant. Therefore, the more time adolescents spend in online communication at $\mathrm{t} t$, the higher the risk that they will engage in cyberbullying at $t 2$.

Model 4 showed that none of the intrapersonal characteristics significantly increased the risk of engaging in cyberbullying at $t 2$ over and above the effect of antisocial behaviours and online communication, which were statistically significant, and experiences of victimisation, which were not statistically significant. These results show that intrapersonal characteristics 
Table 2. Summary of logistic regression analyses

\begin{tabular}{|c|c|c|c|c|c|c|c|c|}
\hline & \multicolumn{2}{|c|}{ Model 1} & \multicolumn{2}{|c|}{ Model 2} & \multicolumn{2}{|c|}{ Model 3} & \multicolumn{2}{|c|}{ Model 4} \\
\hline & OR & $95 \% \mathrm{CI}$ & OR & $95 \% \mathrm{CI}$ & OR & $95 \% \mathrm{Cl}$ & OR & $95 \% \mathrm{CI}$ \\
\hline \multicolumn{9}{|l|}{ Interpersonal characteristics } \\
\hline Traditional bullying t1 & $4.06^{* * * *}$ & $1.85-8.95$ & $3.95^{* * *}$ & $1.75-8.90$ & $4.05^{* * * *}$ & $1.80-9.13$ & $4.25 * * *$ & $1.79-10.08$ \\
\hline Rule-breaking behaviours $\mathrm{t} 1$ & $2.85^{* * * *}$ & $1.63-4.99$ & $2.76^{* * * *}$ & $1.58-4.80$ & $2.38 * *$ & $1.34-4.21$ & $2.16^{*}$ & $1.18-3.97$ \\
\hline Cyber victimisation $\mathrm{t} 1$ & & & 1.59 & $0.90-2.78$ & 1.50 & $0.85-2.64$ & 1.63 & $0.91-2.91$ \\
\hline Traditional victimisation $\mathrm{tl}$ & & & 1.06 & $0.53-2.12$ & 1.16 & $0.58-2.33$ & 1.41 & $0.67-2.94$ \\
\hline Online communication $t 1$ & & & & & $1.37^{*}$ & $1.04-1.79$ & $1.43^{*}$ & $1.08-1.89$ \\
\hline \multicolumn{9}{|l|}{ Intrapersonal characteristics } \\
\hline Gender (female) & & & & & & & 0.81 & $0.46-1.42$ \\
\hline Moral disengagement $\mathrm{t} 1$ & & & & & & & 1.13 & $0.71-0.84$ \\
\hline Empathic concern tl & & & & & & & 0.92 & $0.64-1.32$ \\
\hline Global self-esteem $\mathrm{t} 1$ & & & & & & & 1.23 & $0.79-2.04$ \\
\hline \multicolumn{9}{|l|}{ Control variables } \\
\hline Cyberbullying t1 & $5.19 * * *$ & $3.10-8.70$ & $4.30 * * * *$ & $2.47-7.49$ & $3.93 * * *$ & $2.24-6.88$ & $4.02^{* * * * *}$ & $2.26-7.14$ \\
\hline Traditional bullying $\mathrm{t} 2$ & $4.76^{* * *}$ & $2.50-9.08$ & $5.02 * * *$ & $2.62-9.64$ & $4.97 * * *$ & $2.59-9.56$ & $4.93 * * *$ & $2.49-9.73$ \\
\hline$N$ & 794 & & 792 & & 792 & & 767 & \\
\hline-2 Log likelihood & 432.60 & & 429.68 & & 424.53 & & 404.65 & \\
\hline Nagelkerke $R^{2}$ & .388 & & .393 & & .403 & & .421 & \\
\hline
\end{tabular}

Note. ${ }^{*} p<.05,{ }^{* * *} p<.01, * * * p<.001$. 
do not independently increase the odds of engaging in cyberbullying in the future, when interpersonal characteristics are taken into account.

In all models, both cyberbullying at $\mathrm{t} 1$ and traditional bullying at $\mathrm{t} 2$ were significant at the $p<.001$ level.

\section{DISCUSSION}

The present study investigated the role of interpersonal and intrapersonal characteristics as longitudinal risk factors for cyberbullying. The results showed that the individual tendency to engage in different forms of antisocial behaviour (traditional bullying and rule-breaking behaviour) is the most important risk factor for cyberbullying, followed by the frequency of online communication.

Before the main results are discussed, it is worth taking a closer look at the prevalence of cyberbullying and traditional bullying.

\section{Prevalence of cyberbullying}

Cyberbullying was markedly less prevalent than traditional bullying at both the first and the second assessment. Furthermore, cybervictimisation was found to be less prevalent than traditional victimisation. These results confirm findings from previous studies (e.g. Juvonen \& Gross, 2008; Li, 2007; Smith et al., 2008) and show that the picture of cyberbullying as a highly prevalent and steadily increasing problem is oversimplified. A possible reason for the difference in prevalence may be that adolescents spend most of their time directly interacting with their peers in the real world (e.g. school and after-school activities). In real-world social interactions, traditional forms of bullying may be more likely to be performed than cyberbullying because a target may be directly available (e.g. is physically present) or because the social situation may be such that traditional forms of bullying are a more spontaneous response (e.g. writing an SMS would require more effort). In addition to this possible explanation, differences between the scales used to assess cyberbullying and traditional bullying may also have influenced their apparent prevalence: The cyberbullying scale contains relatively similar items (e.g. sending nasty messages to individuals or groups of individuals), whereas the traditional bullying scale contains more differentiated items (e.g. hitting someone, excluding someone) that may be performed in cyberspace as well. Nevertheless, the cyberbullying scale we used in this study encompasses all major types of cyberbullying that are perceived as relevant at age 13 years: aggressive texting or messaging and sending problematic content in form of pictures or videos (Law et al., 2012; Smith et al., 2008).

\section{Risk factors for engagement in cyberbullying as a bully}

As hypothesised, bivariate analyses indicate that most of the potential risk factors show significant associations with cyberbullying. However, when controlling for past cyberbullying and concurrent traditional bullying, longitudinal analyses yielded a different picture: Antisocial behaviours (traditional bullying and rule-breaking behaviours) and frequent online communication are longitudinal risk factors for cyberbullying, whereas neither experiences of 
victimisation nor intrapersonal characteristics increase the odds of engaging in cyberbullying over and above antisocial behaviours and frequency of online communication.

Traditional bullies are at increased risk of engaging in cyberbullying in the future: Those who attack others in the real world today are more than 4 times as likely to do so in cyberspace a few months later. Another significant longitudinal risk factor for involvement in cyberbullying was found to be rule-breaking behaviour. Adolescents displaying behaviours such as smoking, drinking alcohol, hurting animals, or destroying others' property have twice the risk of getting involved in cyberbullying a few months later. This result adds a longitudinal perspective to the cross-sectional findings of Ybarra and Mitchell (2004), who reported that cyberbullies display more rule-breaking behaviours. Taken together, these findings suggest that adolescents who display some form of antisocial behaviour in the real world are at increased risk of involvement in cyberbullying. These results confirm our hypotheses and show that cyberbullying may be seen as an additional way of attacking people rather than something conceptually different (Gradinger et al., 2010; Raskauskas \& Stoltz, 2007).

In addition to antisocial behaviours, frequency of online communication is another central risk factor for cyberbullying. As hypothesised, the more time adolescents spend communicating online, the higher their risk of engaging in cyberbullying. Moreover, online communication also increases the risk of cybervictimisation (Juvonen \& Gross, 2008). Therefore, the role of online communication may be seen as an exposure effect that might be strongest for adolescents who have the possibility of communicating online from their own room (Law, Shapka, \& Olson, 2010) or from mobile devices.

In contrast to the significant longitudinal role of antisocial behaviours and frequency of online communication, we found that experiences of victimisation and intrapersonal characteristics did not increase the odds of engaging in cyberbullying in the future over and above antisocial behaviours and frequency of online communication. Moreover, neither gender nor global self-esteem was found to be associated with cyberbullying at 12 on a bivariate level. However, global self-esteem was found to be negatively associated with cyberbullying at $t 1$. Our results therefore support those of Smith et al. (2008) and Patchin and Hinduja (2006), who also found no significant association between cyberbullying and gender, and are partly in line with those of Patchin and Hinduja (2010), who found that cyberbullies had lower levels of self-esteem. Although experiences of victimisation and intrapersonal characteristics were not found to be risk factors for future involvement in cyberbullying as a bully, significant bivariate associations with cyberbullying at $t 1$ and $t 2$ were found for experiences of victimisation, moral disengagement, and empathic concern. These variables might play a more central role as risk factors for other forms of bullying (e.g. traditional bullying; Stassen Berger, 2007). However, they have no direct link with changes in cyberbullying behaviours. The bivariate association between cyberbullying and experiences of victimisation, moral disengagement, and empathic concern might be mediated by antisocial behaviours: those who experienced victimisation, who have high moral disengagement scores, or who lack empathic concern may be more prone to traditional forms of antisocial behaviours and, therefore, be inclined to cyberbullying in an indirect way.

It is important to note that the inclusion of cyberbullying at $t 1$ and traditional bullying at $\mathrm{t} 2$ and all other predictors means that experiences of victimisation and intrapersonal characteristics have no predictive value for changes in pure cyberbullying, when all other predictors are taken into account. In summary, the present data suggest that involvement in cyberbullying does not directly depend on experiences of victimisation or intrapersonal 
characteristics but on the individual tendency to engage in antisocial behaviours, including past acts of cyberbullying, and on the frequency of online communication.

In the light of these findings, some conclusions about the prevention of cyberbullying can be drawn. Given that traditional bullying is the strongest longitudinal risk factor for cyberbullying, prevention programs against traditional bullying may indirectly target cyberbullying too (Salmivalli, Kärnä, \& Poskiparta, 2011). Examples of such intervention programs are the Olweus Bullying Prevention Program (Olweus, 1991), which inspired most antibullying programs developed over the last 20 years (for review, see Farrington \& Ttofi, 2009), and the KiVa Antibullying Program (Salmivalli, Kärnä, \& Poskiparta, 2010), which focuses on the role of bystander behaviour in the effective prevention of bullying. The general prevention of antisocial behaviours also plays a key role in preventing cyberbullying. A number of programs combating antisocial behaviours, such as The First Step program (Walker et al., 1998) or The Incredible Years program (Reid, Webster-Stratton, \& Hammond, 2007), have been developed over the last decades. A central element of these programs is the development of social skills and competences and positive interpersonal relationships to support social and school adjustment (Mcloughlin, 2009).

Finally, our results suggest that reducing the frequency of online communication also reduces the risk of engaging in cyberbullying. Although this is a logical conclusion, it is important to note that electronic forms of communication are just tools and not in themselves the causes of problematic behaviours (Juvonen \& Gross, 2008). Therefore, the focus should be on the prevention of specific risk factors and on the promotion of safety on the Internet rather than on the frequency of online communication per se. Education in cybersafety strategies might help to reduce a variety of risky behaviours, such as publishing private content or giving away passwords. A comprehensive list of online risks and respective cybersafety strategies (e.g. raising awareness, targeting young users, creating industry support for internet safety) was proposed by Livingstone, Haddon, Görzig, and Ólafsson (2011).

Because cyberbullying is related to other group dynamics (e.g. traditional bullying) and aggressive behaviours emerge early in childhood (Monks, 2011), there is a need for comprehensive programs that are able to target different antisocial behaviours (Bostic \& Brunt, 2011) starting as early as preschool (Monks, 2011). Furthermore, preventive efforts need to involve and to actively support both the school and the parents in their efforts to deliver the prevention program (Smith, 2011b).

\section{Strengths and limitations}

This study considered a set of potential risk factors for involvement in cyberbullying, elucidating their independent roles. The simultaneous inclusion of traditional bullying, rulebreaking behaviours, traditional victimisation, and cybervictimisation as potential risk factors for cyberbullying led to very differentiated results. Furthermore, the use of a longitudinal design enabled us to shed light on the direction of causal effects.

There are, however, some limitations to the present findings that need to be borne in mind. First, the exclusive use of self-reports may have led to underreporting of antisocial behaviours, thereby compromising the validity of the information (Brown \& Zimmermann, 2004). Second, the scales of cyberbullying, cybervictimisation, traditional bullying, and traditional victimisation show low to moderate internal consistencies. This reflects the fact that most adolescents show/suffer only one or two behaviours listed in the respective scales, and, therefore, the internal consistencies cannot be expected to be high. A third 
limitation is that some important potential risk factors could not be included in our study (e.g. intelligence, personality, socioeconomic status, social context; Welsh \& Farrington, 2007). These elements would give a more detailed picture of the characteristics that contribute independently to the development of cyberbullying. Last but not least, the time interval of 6 months between assessments is very short.

\section{Conclusion}

Taken together, these findings show that interpersonal characteristics such as antisocial behaviours and frequent online communication are the most prominent longitudinal risk factors for involvement in cyberbullying. The results also show that it is necessary to take a broad view of the phenomenon of cyberbullying. Models that do not include aggressive and antisocial behaviours may overestimate the independent role of certain characteristics as risk factors. Our results and those of other studies (Gradinger et al., 2010; Juvonen \& Gross, 2008) suggest that cyberbullying can be seen as an online version of other real-world antisocial behaviours, and so prevention of cyberbullying should focus on early prevention of different forms of antisocial behaviour.

\section{ACKNOWLEDGEMENTS}

This study was supported by a grant from the Swiss National Science Foundation (SNF No. 100014_130193/1) to the second author. The authors would like to acknowledge the collaboration of all students involved in data collection. Furthermore, we would like to thank all study participants and teachers for the participation over the whole duration of the study.

\section{REFERENCES}

ABC News. (2007). Parents: Cyber bullying led to teen's suicide. Retrieved November, 16, 2011, from http://abcnews.go.com/GMA/story?id=3882520\&page=1

Alsaker, F. D. (2003). Quälgeister und ihre Opfer. Mobbing unter Kindern - und wie man damit umgeht. Bern: Huber Verlag.

Ang, R. P., \& Goh, D. H. (2010). Cyberbullying among adolescents: The role of affective and cognitive empathy, and gender. Child Psychiatry and Human Development, 4l(4), 387-397.

Bauman, S. (2009). Cyberbullying in a rural intermediate school: An exploratory study. Journal of Early Adolescence, 30(6), 803-833.

Bostic, J. Q., \& Brunt, C. C. (2011). Cornered: An approach to school bullying and cyberbullying, and forensic implications. Child and Adolescent Psychiatric Clinics of North America, 20, 447-465.

Brown, T. L., \& Zimmermann, R. S. (2004). Are adolescents accurate reporters of their alcohol use? Individual Differences Research, 2(1), 17-25.

Caravita, S. C. S., Di Blasio, P., \& Salmivalli, C. (2009). Unique and interactive effects of empathy and social status on involvement in bullying. Social Development, 18(1), 140-163.

Collani, G., \& Herzberg, P. Y. (2003). Eine revidierte Fassung der deutschsprachigen Skala zum Selbstwertgefühl von Rosenberg. Zeitschrift fir Differentielle und Diagnostische Psychologie, 24(1), 3-7.

Dooley, J. J., Pyzalski, J., \& Cross, D. (2009). Cyberbullying versus face-to-face bullying: A theoretical and conceptual review. Journal of Psychology, 217(4), 182-188.

Erdur-Baker, Ö. (2010). Cyberbullying and its correlation to traditional bullying, gender, and frequent and risky usage of internet-mediated communication tools. New Media and Society, 2l(1), 109-125.

Farrington, D. P., \& Ttofi, M. M. (2009). School based programmes to reduce bullying and victimization. Campbell Systematic Reviews, 2009:6. Retrieved online from http://www.crim.cam.ac.uk/people/ academic_research/david_farrington/bullcamp.pdf 
Gradinger, P., Strohmeier, D., \& Spiel, C. (2010). Definition and measurement of cyberbullying. Cyberpsychology: Journal of Psychosocial Research on Cyberspace, 4, article 1. Retrieved July 18, 2011, from http://cyberpsychology.eu/view.php?cisloclanku=2010112301\&article=1

Jolliffe, D., \& Farrington, D. P. (2004). Empathy and offending: A systematic review and meta-analysis. Aggressive and Violent Behavior, 9, 441-476.

Jolliffe, D., \& Farrington, D. P. (2011). Is low empathy related to bullying after controlling for individual and social background variables? Journal of Adolescence, 34, 59-71.

Juvonen, J., \& Gross, E. F. (2008). Extending the school grounds? Bullying experiences in cyberspace. Journal of School Health, 78(9), 496-505.

Kowalski, R. M., \& Limber, S. P. (2007). Electronic bullying among middle school students. Journal of Adolescent Health, 41(6), 22-30.

Law, D. M., Shapka, J. D., Hymel, S., Olson, B. F., \& Waterhouse, T. (2012). The changing face of bullying: An empirical comparison between traditional and Internet bullying and victimization. Computers in Human Behavior, 28, 226-232.

Law, D. M., Shapka, J. D., \& Olson, B. F. (2010). To control or not to control? Parenting behaviours and adolescent online aggression. Computers in Human Behavior, 26, 1651-1656.

Li, Q. (2007). New bottle but old wine: A research on cyberbullying in schools. Computers in Human Behavior, 23(4), 1777-1791.

Livingstone, S., Haddon, L., Görzig, A., \& Ólafsson, K. (2011). Risks and Safety on the Internet: The Perspective of European Children. Full Findings. LSE, London: EU Kids Online.

Malti, T., Gummerum, M., Keller, M., \& Buchmann, M. (2009). Children's moral motivation, sympathy, and prosocial behavior. Child Development, 80, 442-460.

Mcloughlin, C. (2009). Positive peer group interventions: An alternative to individualized interventions for promoting prosocial behavior in potentially disaffected youth. Electronic Journal of Research in Educational Psychology, 7(3), 1131-1156.

Menesini, E., Sanchez, V., Fonzi, A., Ortega, R., Costabile, A., \& Lo Feudo G. (2003). Moral emotions and bullying. A cross-sectional comparison of differences between bullies, victims, an outsiders. Aggressive Behavior, 29, 515-530.

Mitchell, K. J., Finkelhor, D., Wolak, J., Ybarra, M. L., \& Turner, H. (2011). Youth Internet victimization in a broader victimization context. Journal of Adolescent Health, 2, 128-134.

Monks, C. P. (2011). Peer-victimisation in preschool. In C. P. Monks, \& I. Coyne (Eds.), Bullying in different contexts (pp. 12-35). Cambridge: Cambridge university press.

Nocentini, A., Calmaestra, J., Schulze-Krumbholz, A., Scheithauer, H., Ortega, R., \& Menesini, E. (2010). Cyberbullying: Labels, definitions and behaviors in three countries. Australian Journal of Guidance and Counselling, 20(2), 129-142.

Olweus, D. (1991). Bully/victim problems among children: Basic facts and effects of a school based intervention program. In D. Pepler, \& K. Rubin (Eds.), The development and treatment of childhood aggression (pp. 411-448). Hillsdale, NJ: Erlbaum.

Olweus, D. (1993). Bullying at school: What we know and what we can do. Oxford: Blackwell Publishers.

Olweus, D. (2010). Understanding and researching bullying: Some critical issues. In S. R. Jimerson, S. M. Swearer, \& D. L. Espelage (Eds.), The handbook of school bullying: An international perspective (pp. 9-33). New York: Routledge.

Patchin, J. W., \& Hinduja, S. (2006). Bullies move beyond the schoolyard: A preliminary look at cyberbullying. Youth Violence and Juvenile Justice, 4(2), 148-169.

Patchin, J. W., \& Hinduja, S. (2010). Cyberbullying and self-esteem. Journal of School Health, 80 (12), 614-621.

Perren, S., \& Gutzwiller-Helfenfinger, E. (2012). Cyberbullying and traditional bullying in adolescence: Differential roles of moral disengagement, moral emotions, and moral values. The European Journal of Developmental Psychology, 9(2), 195-209.

Perren, S., Gutzwiller-Helfenfinger, E., Malti, T., \& Hymel, S. (2011). Moral reasoning and emotion attributions of adolescent bullies, victims, and bully-victims. British Journal of Developmental Psychology. Published online first, doi: 10.1111/j.2044-835X.2011.02059.x

Perren, S., Rumetsch, U., Gutzwiller-Helfenfinger, E., \& Malti, T. (2012). Moral Justifications for Bullying (MOJUS): The Development of a Survey Measure. Submitted for publication. 
Pornari, C. D., \& Wood, J. (2010). Peer and cyberbullying in secondary school students: The role of moral disengagement, hostile attribution bias, and outcome expectancies. Aggressive Behavior, 36, 81-94.

Raskauskas, J., \& Stoltz, A. D. (2007). Involvement in traditional and electronic bullying among adolescents. Developmental Psychology, 43, 564-575.

Reid, J. M., Webster-Stratton, C., \& Hammond, M. (2007). Enhancing a classroom social competence and problem-solving curriculum by offering parent training to families of moderate- to high-risk elementary school children. Journal of Clinical Child and Adolescent Psychology, 36(4), 605-620.

Salmivalli, C., Kärnä, A., \& Poskiparta, E. (2010). Development, evaluation, and diffusion of a national antibullying program, KiVa. In B. Doll, W. Pfohl, \& J. Yoon (Eds.), Handbook of youth prevention science (pp. 238-252). New York: Routledge.

Salmivalli, C., Kärnä, A., \& Poskiparta, E. (2011). Counteracting bullying in Finland: The KiVa program and its effects on different forms of being bullied. International Journal of Behavioral Development, 35, 405-411.

Schultze-Krumbholz, A., \& Scheithauer, H. (2009). Social-behavioral correlates of cyberbullying in a German student sample. Journal of Psychology, 217(4), 224-226.

Slonje, R., \& Smith, P. K. (2008). Cyberbullying: Another main type of bullying? Scandinavian Journal of Psychology, 49, 147-154.

Smith, P. K. (2011a). Cyberbullying and cyber aggression. In S. R. Jimerson, A. B. Nickerson, M. J. Mayer, \& M. J. Furlong (Eds.), Handbook of school violence and school safety: International research and practice. New York: Routledge.

Smith, P. K. (2011b). Bullying in schools: Thirty years of research. In C. P. Monks, \& I. Coyne (Eds.), Bullying in different contexts (pp. 36-60). Cambridge: Cambridge university press.

Smith, P. K., \& Slonje, R. (2010). Cyberbullying: the nature and extent of a new kind of bullying, in and out of school. In S. Jimerson, S. Swearer, \& D. Espelage (Eds.) Handbook of bullying in schools (pp. 249-262). New York: Routledge.

Smith, P. K., Mahdavi, J., Carvalho, M., Fisher, S., Russell, S., \& Tippet, N. (2008). Cyberbullying: Its nature and impact in secondary school pupils. Journal of Child Psychology and Psychiatry, 49, 376-385.

Sourander, A., Klomek, A. B., Ikonen, M., Lindroos, J., Luntamo, T., Koskelainen, M., . . Helenius, H. (2010). Psychosocial risk factors associated with cyberbullying among adolescents: A populationbased study. Archives of General Psychiatry, 67(7), 720-728.

Stassen Berger, K. (2007). Update on Bullying at School: Science Forgotten? Developmental Review, $27(1), 90-126$.

Steffgen, G., König, A., Pfetsch, J., \& Metzler, A. (2012). Are cyberbullies less empathic? Adolescents' cyberbullying behavior and empathic responsiveness. Cyberpsychology, Behavior, and Social Psychology, 14(11), 643-648.

Sutton, J., Smith, P. K., \& Swettenham, J. (1999). Bullying and ,theory of mind": A critique of the ,social skills deficit" approach to anti-social behavior. Social Development, 8, 117-127.

Tokunaga, R. (2010). Following you home from school: A critical review and synthesis of research on cyberbullying victimization. Computers in Human Behaviour, 26, 277-287.

Vandebosch, H., \& Van Cleemput, K. (2009). Cyberbullying among youngsters: Profiles of bullies and victims. New Media \& Society, 11(8), 1349-1371.

Walker, H. M., Kavanagh, K., Stiller, B., Golly, A., Severson, H. H., \& Feil, E. G. (1998). First Step to Success: An early intervention approach for preventing school antisocial behavior. Journal of Emotional and Behavioral Disorders, 6(2), 6-80.

Welsh, B. C., \& Farrington, D. P. (2007). Saving children from a life of crime: Toward a national strategy of early prevention. Victims and Offenders, 2, 1-20.

Willemse, I., Waller, G., \& Süss, D. (2010). JAMES - Jugend. Aktivitäten, Medien - Erhebung Schweiz. Zürcher Hochschule für Angewandte Wissenschaften, Zürich.

Yadava, A., Sharma, N. R., \& Gandhi, A. (2001). Aggression and moral disengagement. Journal of Personality and Clinical Studies, 17, 95-99.

Ybarra, M. L., \& Mitchell, K. J. (2004). Online aggressors/targets, aggressors, and targets: A comparison of associated Youth characteristics. Journal of Child Psychology and Psychiatry, 45 (7), 1308-1316.

Zhou, Q., Valiente, C., \& Eisenberg, N. (2003). Empathy and its measurement. In S. J. Lopez, \& C. R. Snyder (Eds.), Positive psychological assessment: The handbook of models and measures (pp. 269-284). Washington, DC: American Psychological Association. 


\section{APPENDIX 1}

Cyberbullying scale

How often did you do the following things since the beginning of the school year?

\begin{tabular}{|c|c|c|c|c|c|c|}
\hline & Never & $\begin{array}{c}1-2 \\
\text { times }\end{array}$ & $1 \times /$ month & $1 \times /$ week & $\begin{array}{l}\text { Almost } \\
\text { daily }\end{array}$ & $\begin{array}{c}\text { No } \\
\text { response }\end{array}$ \\
\hline $\begin{array}{l}\text { Have you sent mean or threatening } \\
\text { messages to anyone (text messages, } \\
\text { MSN, Facebook, etc.) }\end{array}$ & $\square$ & $\square$ & $\square$ & $\square$ & $\square$ & $\square$ \\
\hline $\begin{array}{l}\text { Have you sent mean or threatening } \\
\text { pictures or videos to anyone (picture } \\
\text { messages, Facebook, etc.)? }\end{array}$ & $\square$ & $\square$ & $\square$ & $\square$ & $\square$ & $\square$ \\
\hline $\begin{array}{l}\text { Have you sent mean or embarrassing } \\
\text { messages or spread rumours about } \\
\text { anyone to your friends (text messages, } \\
\text { MSN, Facebook, etc.)? }\end{array}$ & $\square$ & $\square$ & $\square$ & $\square$ & $\square$ & $\square$ \\
\hline $\begin{array}{l}\text { Have you sent mean or embarrassing } \\
\text { pictures or videos of anyone to your } \\
\text { friends (picture messages, } \\
\text { Facebook, etc.)? }\end{array}$ & $\square$ & $\square$ & $\square$ & $\square$ & $\square$ & $\square$ \\
\hline $\begin{array}{l}\text { Have you posted mean or } \\
\text { embarrassing messages } \\
\text { or spread rumours about } \\
\text { anyone on the Internet } \\
\text { (Facebook, YouTube, etc.)? }\end{array}$ & $\square$ & $\square$ & $\square$ & $\square$ & $\square$ & $\square$ \\
\hline $\begin{array}{l}\text { Have you posted mean or embarrassing } \\
\text { pictures or videos of anyone on the } \\
\text { Internet (Facebook, YouTube, etc.)? }\end{array}$ & $\square$ & $\square$ & $\square$ & $\square$ & $\square$ & $\square$ \\
\hline
\end{tabular}

